\title{
DIRECTIONS FOR IMPROVING ADAPTIVE MANAGEMENT EFFICIENCY OF MANUFACTURING PHARMACEUTICAL COMPANIES
}

\author{
Rita Sahaidak-Nikitiuk $\bowtie$ \\ Department of Management and Economics of Enterprise ${ }^{I}$ \\ management@nuph.edu.ua
}

Karyna Holybtsova

Postgraduate Studies Department ${ }^{1}$

Nataliya Demchenko

Department of Management and Administration ${ }^{1}$

Vitalii Nikitiuk

Sector of Weapons examination

National Scientific Center «Hon. Prof. M. S. Bokarius Forensic Science Science Institute»

8 a Zolochivska str., Kharkiv, Ukraine, 61177

${ }^{I}$ National University of Pharmacy

53 Pushkinska str., Kharkiv, Ukraine, 61002

$\triangle$ Corresponding author

\begin{abstract}
The aim of the article is to analyze the existing problems of adaptive management of manufacturing pharmaceutical companies and the development of methodological support for their management.

Materials and methods. The research used methods of theoretical generalization, analysis and synthesis, synergetic approach and expert survey.

120 people were involved in the expert survey, divided into four groups: representatives of pharmaceutical manufacturing enterprises (30 people); representatives of pharmaceutical higher education institutions (30 people); pharmaceutical distributors representing wholesale companies ( 30 people); end users (30 people).

Results. The article considers scientific and methodological approaches to improving adaptive management in the direction of forming competitive advantages of manufacturing pharmaceutical companies, the practical implementation of which requires business entities determination, flexibility and adequacy in the formation of modern management strategies and tactical planning and operational tasks of production, economic and commercial activities. There are external and internal factors influencing the formation of competitive advantages of the business entity. As the internal factors we include: organizational and legal form, and business entity organizational structure; the level of scientific and technical development of production; level of education and qualification of staff; business image of the enterprise; financial reputation of the enterprise. However, no less influence on the formation of competitive advantages of the management of manufacturing pharmaceutical companies have external factors, which, in contrast to internal, are not controlled by the entity: the state of the pharmaceutical market; technologies; workforce; scientific and technical development; etc.

Conclusions. The directions of increasing the adaptive management efficiency are determined and it is concluded that the main criterion of efficiency is the quality of pharmaceutical products and the quality of management decisions in economic risks.

Keywords: adaptive control, pharmaceutical manufacturing company, methodological support, drug.
\end{abstract}

DOI: $10.21303 / 2504-5679.2021 .002052$

\section{Introduction}

Issues of competitiveness in all sectors in the national economy come to the fore, as the achievement of scientific and technological progress and using new technologies require businesses to such a level of production that would meet global requirements and strengthen competitive positions in the international market. In this regard, gaining competitive advantage by economic entities through the improvement of existing management systems, as a more important component of production, economic and commercial activities, is a priority for the management of manufacturing pharmaceutical companies (MPhCo). 
Problems of adaptive management development of industrial enterprises were studied in scientific works [1, 2], questions of Quality of Adaptive Management [3], questions of pharmaceutical enterprises' management $[4,5]$, problems of adaptive management development of pharmaceutical enterprises' management [6,7], risk-management of pharmaceutical companies [8], logistic management of enterprises [9, 10], macroenvironment activities of organizations [11], competitiveness of companies $[12,13]$, etc.

Nevertheless, the issues of methodological support for adaptive management of the MPhCo are not sufficiently addressed and need further development.

The aim of the study. The purpose of the article is to analyze the existing problems of adaptive management of $\mathrm{MPhCo}$ and to work out the methodological support for management.

\section{Materials and methods}

The methods used in the study include methods of theoretical generalization, analysis and synthesis, synergetic approach and expert questioning.

120 people were involved in the expert survey in January-June 2019, divided into four groups: representatives of pharmaceutical manufacturing enterprises (30 people); representatives of the pharmaceutical industry (30 people); pharmaceutical distributors representing wholesale companies (30 people); end users (30 people). The object of examination are the factors influencing the adaptive management level of the MPhCo:

1. Introduction of innovative production technologies.

2. State financial support of the pharmaceutical industry.

3. Antitrust regulation.

4. Material, technical base and production processes updating in MPhCo.

5. Quality and availability of domestic medicines.

6. Advertising, PR, membership in associations.

7. Application of marketing and logistics tools.

8. Optimization of work with suppliers.

9. Personnel potential preservation in the MPhCo.

10. Organization, methodical support of patent work of the pharmaceutical industry enterprises and institutions.

The indicators were evaluated according to a 5-point system: from «1» (does not affect at all) to «5» (the factor influence on the adaptive management level of the MPhCo is the highest).

According to Snela-Kemeny theory, a measure of proximity was established, it allows to determine the distance between any pair of binary relations.

\section{Results}

The most effective for the national economy of Ukraine is the adaptive management of economic entities. Of particular importance for the adaptive management of MPhCo is the ratio of accuracy and speed of management response to changes in the external environment, i. e. the ratio of accuracy and speed of directed changes in the internal environment of the enterprise compared to the speed and direction of changes in the external environment $[14,15]$.

The main criterion for the adaptive management effectiveness of MPhCo is the pharmaceutical products quality and the quality of management decisions according to economic risks.

Approaches to risk management are traditionally based on a number of organizational and economic measures aimed at preventing and reducing the likelihood of their occurrence. These include, in particular:

- availability of reliable, timely, complete information;

- control effects on MPhCo, which reduce the likelihood of environmental risk and reduce their negative consequences;

- use of regulatory materials to respond quickly and appropriately to the emergence of risky situations;

- availability of developed infrastructure (transport, storage, etc.);

- MPhCo activity insurance [16]. 
In our opinion, the set of methods for managing the economic risks of the MPhCo is quite diverse, which is often due to the financial condition of the enterprise, the conditions of production and economic activity and market position. In this regard, the application of an adaptive approach to economic risk management in conjunction with the tools of process, crisis and innovation approaches is the most acceptable for the pharmaceutical industry (Fig. 1).

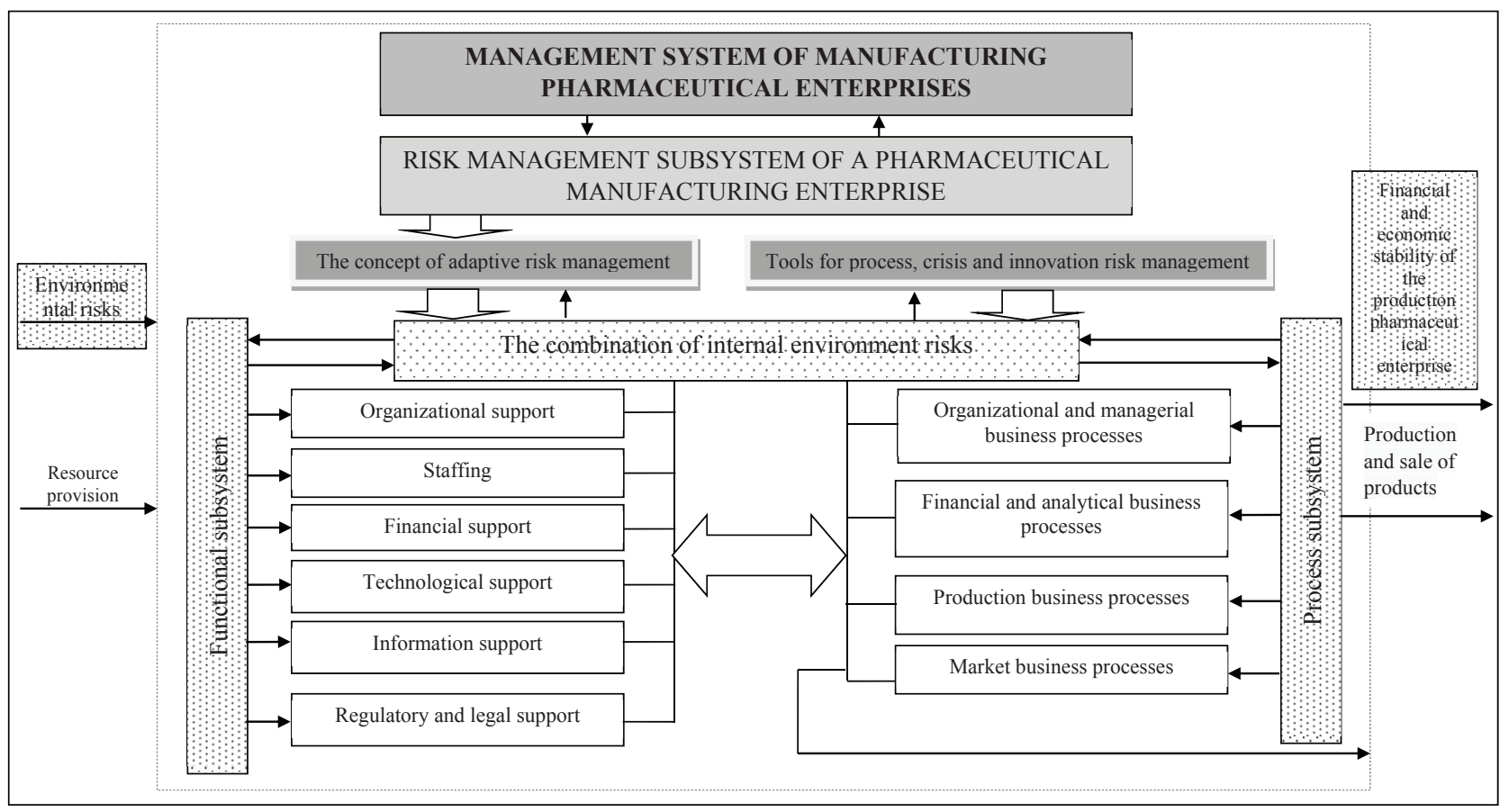

Fig. 1. Economic risk management system of a manufacturing pharmaceutical company

It should be noted that the use of a combination of these methods is appropriate in case of need to respond quickly to abrupt changes in the external and internal environment of the MPhCo.

The complexity of production, social and other factors of the external and internal environment of the MPhCo require adequate action by management. In such circumstances, management decisions can be made either quickly (based on existing experience) or on the basis of thorough analysis and application of modelling and forecasting methods [17].

There are external and internal factors influencing the formation of competitive advantages of the business entity.

The internal factors we include:

- organizational and legal form and business entity organizational structure;

- the level of scientific and technical development of production;

- level of education and qualification of staff;

- business image of the enterprise;

- financial reputation of the enterprise.

However, no less influence on the formation of competitive advantages of the MPhCo have external factors, which, in contrast to internal, are not controlled by the entity:

- the state of the pharmaceutical market;

- technologies;

- workforce;

- scientific and technical development;

- degree of state regulation, etc.

Improving adaptive management in the direction of forming the competitive advantages of the MPhCo should be considered in the context of following factors of influence: socio-economic, organizational-economic, organizational-legal, organizational-technical, organizational-technological. 
Socio-economic factors determine the set of social relations within which the enterprise management system operates.

Organizational and economic factors determine the existence of institutions established in the form of laws or institutions, including financial, through which certain aspects of the activities of economic entities.

Organizational and legal factors are related to the presence or absence of the appropriate regulatory framework necessary for the effective implementation of the MPhCo activities.

Organizational and technical factors reflect the level of equipment and technologies development that necessary for the practical implementation of production, economic and commercial activities of the MPhCo.

Organizational and technological factors reflect the structure of making and implementing management decisions in the process of functioning of the MPhCo in the system of sectoral and national economic development [18].

The results of expert assessment of factors influencing the adaptive management level of the $\mathrm{MPhCo}$ by representatives of enterprises are given in Table $\mathbf{1 .}$

Table 1

The results of expert assessment of factors influencing the adaptive management level of the MPhCo by representatives of enterprises

\begin{tabular}{|c|c|c|c|c|c|c|}
\hline \multirow{2}{*}{\multicolumn{2}{|c|}{ Criterion }} & \multicolumn{5}{|c|}{ Rating } \\
\hline & & 1 & 2 & 3 & 4 & 5 \\
\hline & Introduction of innovative production technologies & 1 & 3 & 7 & 7 & 12 \\
\hline 2 & State financial support of the pharmaceutical industry & 2 & 5 & 6 & 9 & 8 \\
\hline 3 & Marketing and logistics tools application & 3 & 5 & 8 & 8 & 6 \\
\hline & Optimization of work with suppliers & 0 & 0 & 3 & 11 & 16 \\
\hline & Quality and availability of domestic medicines & 2 & 1 & 6 & 12 & 9 \\
\hline 6 & Advertising, PR, membership in associations & 4 & 8 & 8 & 6 & 4 \\
\hline 7 & Antitrust regulation & 5 & 11 & 8 & 3 & 3 \\
\hline 8 & Personnel potential preservation in the $\mathrm{MPhCo}$ & 0 & 2 & 7 & 11 & 10 \\
\hline 9 & Material, technical base and production processes updating in MPhCo & 2 & 2 & 5 & 10 & 11 \\
\hline 10 & Organization, methodical support of patent work at enterprises and institutions of the pharmaceutical industry & 4 & 7 & 8 & 5 & 6 \\
\hline
\end{tabular}

The results of expert assessment of factors influencing the adaptive management level of MPhCo by representatives of pharmaceutical higher education institutions of the pharmaceutical industry are given in Table 2.

Table 2

The results of expert assessment of factors influencing the adaptive management level of MPhCo by representatives of pharmaceutical higher education institutions of the pharmaceutical industry

\begin{tabular}{|c|c|c|c|c|c|c|}
\hline & \multirow{2}{*}{ Criterion } & \multicolumn{5}{|c|}{ Rating } \\
\hline & & 1 & 2 & 3 & 4 & 5 \\
\hline & Introduction of innovative production technologies & 1 & 4 & 8 & 10 & 7 \\
\hline 2 & State financial support of the pharmaceutical industry & 2 & 2 & 7 & 11 & 8 \\
\hline 3 & Marketing and logistics tools application & 1 & 5 & 9 & 7 & 8 \\
\hline 4 & Optimization of work with suppliers & 1 & 4 & 10 & 10 & 6 \\
\hline 5 & Quality and availability of domestic medicines & 3 & 3 & 7 & 8 & 9 \\
\hline 6 & Advertising, PR, membership in associations & 3 & 6 & 10 & 6 & 5 \\
\hline 7 & Antitrust regulation & 1 & 5 & 8 & 9 & 7 \\
\hline 8 & Personnel potential preservation in the MPhCo & 5 & 6 & 7 & 6 & 6 \\
\hline 9 & Material, technical base and production processes updating in $\mathrm{MPhCo}$ & 0 & 4 & 9 & 8 & 9 \\
\hline 10 & Organization, methodical support of patent work of the pharmaceutical industry enterprises and institu & 4 & 8 & 5 & 7 & \\
\hline
\end{tabular}


The results of expert assessment of the factors influencing the adaptive management level of MPhCo by pharmaceutical distributors' representatives are given in Table 3.

Table 3

The results of expert assessment of the factors influencing the adaptive management level of MPhCo by pharmaceutical distributors' representatives (wholesale companies)

\begin{tabular}{|c|c|c|c|c|c|c|}
\hline & \multirow{2}{*}{ Criterion } & \multicolumn{5}{|c|}{ Rating } \\
\hline & & 1 & 2 & 3 & 4 & 5 \\
\hline 1 & Introduction of innovative production technologies & 0 & 1 & 8 & 11 & 10 \\
\hline 2 & State financial support of the pharmaceutical industry & 6 & 10 & 5 & 5 & 4 \\
\hline 3 & Marketing and logistics tools application & 3 & 3 & 10 & 6 & 8 \\
\hline 4 & Optimization of work with suppliers & 5 & 5 & 7 & 6 & 7 \\
\hline 5 & Quality and availability of domestic medicines & 1 & 10 & 11 & 6 & 2 \\
\hline 6 & Advertising, PR, membership in associations & 0 & 5 & 8 & 8 & 9 \\
\hline 7 & Antitrust regulation & 2 & 3 & 8 & 7 & 10 \\
\hline 8 & Personnel potential preservation in the $\mathrm{MPhCo}$ & 2 & 2 & 9 & 12 & 5 \\
\hline 9 & Material, technical base and production processes updating in $\mathrm{MPhCo}$ & 3 & 7 & 9 & 6 & 5 \\
\hline 10 & Organization, methodical support of patent work of the pharmaceutical industry enterprises and institutions & 3 & 7 & 6 & 6 & 8 \\
\hline
\end{tabular}

The results of expert assessment of factors influencing the adaptive management level of MPhCo by final users are given in Table 4.

\section{Table 4}

The results of expert assessment of factors influencing the adaptive management level of MPhCo by final users

\begin{tabular}{|c|c|c|c|c|c|c|}
\hline & \multirow{2}{*}{ Criterion } & \multicolumn{5}{|c|}{ Rating } \\
\hline & & 1 & 2 & 3 & 4 & 5 \\
\hline 1 & Introduction of innovative production technologies & 0 & 0 & 1 & 14 & 15 \\
\hline 2 & State financial support of the pharmaceutical industry & 4 & 2 & 8 & 10 & 6 \\
\hline 3 & Marketing and logistics tools application & 4 & 1 & 7 & 9 & 9 \\
\hline 4 & Optimization of work with suppliers & 1 & 5 & 10 & 7 & 7 \\
\hline 5 & Quality and availability of domestic medicines & 2 & 8 & 7 & 8 & 5 \\
\hline 6 & Advertising, PR, membership in associations & 3 & 7 & 6 & 11 & 3 \\
\hline 7 & Antitrust regulation & 6 & 8 & 6 & 6 & 4 \\
\hline 8 & Personnel potential preservation in the $\mathrm{MPhCo}$ & 4 & 6 & 7 & 8 & 5 \\
\hline 9 & Material, technical base and production processes updating in MPhCo & 1 & 3 & 9 & 8 & 9 \\
\hline 10 & Organization, methodical support of patent work of the pharmaceutical industry enterprises and institutions & 7 & 8 & 7 & 4 & 4 \\
\hline
\end{tabular}

Therefore, it can be argued that conducting an expert assessment on a representative sample of respondents, correctly grouped, gives the correct result when using any classical methods of mathematical statistics.

According to the Kemeni procedure [19] an auxiliary collective ordering in each expert group is formed, the closest to all individual orders, which is presented as a collective (group) choice.

The results of the calculations of the elements of the loss matrix, calculated according to the matrices of the relations of assessment of the importance of factors influencing the level of MPhCo' adaptive management of the four expert groups, are given in Table $\mathbf{5}$. 
Table 5

Loss matrix, total distances and ranking of the assessment of the importance of factors influencing the level of adaptive management of the MPhCo

\begin{tabular}{ccccccccccccc}
\hline $\boldsymbol{d}$ & $\mathbf{1}$ & $\mathbf{2}$ & $\mathbf{3}$ & $\mathbf{4}$ & $\mathbf{5}$ & $\mathbf{6}$ & $\mathbf{7}$ & $\mathbf{8}$ & $\mathbf{9}$ & $\mathbf{1 0}$ & $\boldsymbol{C}\left(\boldsymbol{P}_{\boldsymbol{v}}\right)$ & Rank \\
\hline 1 & 4 & 2 & 1 & 3 & 2 & 1 & 2 & 1 & 2 & 0 & 18 & $\mathbf{1}$ \\
2 & 6 & 4 & 4 & 5 & 4 & 2 & 3 & 3 & 5 & 2 & 38 & $\mathbf{5}$ \\
3 & 7 & 4 & 4 & 4 & 4 & 2 & 3 & 2 & 5 & 1 & 36 & $\mathbf{4}$ \\
4 & 5 & 3 & 4 & 4 & 3 & 3 & 4 & 3 & 4 & 1 & 34 & $\mathbf{3}$ \\
5 & 6 & 4 & 4 & 5 & 4 & 3 & 4 & 4 & 5 & 1 & 40 & $\mathbf{6}$ \\
6 & 7 & 6 & 6 & 5 & 6 & 4 & 5 & 5 & 7 & 2 & 53 & $\mathbf{9}$ \\
7 & 6 & 5 & 5 & 4 & 4 & 3 & 4 & 5 & 6 & 1 & 43 & $\mathbf{8}$ \\
8 & 6 & 5 & 4 & 5 & 4 & 3 & 4 & 4 & 6 & 1 & 42 & $\mathbf{7}$ \\
9 & 6 & 3 & 3 & 4 & 3 & 2 & 3 & 3 & 4 & 1 & 32 & $\mathbf{2}$ \\
10 & 8 & 6 & 7 & 7 & 7 & 6 & 7 & 7 & 7 & 4 & 66 & $\mathbf{1 0}$
\end{tabular}

\section{Discussion}

According to the results of the expert evaluation analysis, it can be argued that based on the ranking of the assessment of the importance of factors influencing the level of adaptive management of the MPhCo, the agreed opinion of all groups of experts can be represented as ranking priorities:

1. Introduction of innovative production technologies.

2. Updating the material and technical base and production processes of the MPhCo.

3. Optimization of work with suppliers.

4. Application of marketing and logistics tools.

5. State financial support for the pharmaceutical industry.

6. Quality and availability of domestic medicines.

7. Maintaining the human resources potential of the MPhCo.

8. Antimonopoly regulation.

9. Advertising, public relations, membership in associations.

10. Methodological support of patent work at enterprises and institutions in pharmaceutical industry.

The main areas of improving the adaptive management efficiency of the MPhCo are the following conceptual provisions:

- ability to react to projected changes in the environment and the application of relevant management approaches;

- solving the problems of uncertainty and manoeuvrability of the parameters of the enterprise in terms of its economic growth and development;

- considering the heterogeneity of elements in the development process;

- adequacy of decisions on the development and real state of the enterprise;

- multicriteria evaluation of the enterprise development efficiency;

- the possibility of formulating management criteria based on analytical conclusions and results of control and coordination of development processes [20].

However, taking into account the specifics of the pharmaceutical business and the peculiarities of the management organization in $\mathrm{MPhCo}$, in our opinion, the main areas of improving the adaptive management efficiency are:

- development and implementation of the target program of enterprise development, which considered possible stochastic changes in the external environment;

- development and calculation of a system of indicators that adequately reflect the current (actual) and planned state of the enterprise and the external environment;

- system of goals formation (target functions of development) of the enterprise, which takes into account the need for strategic positioning in the external environment; 
- efficient use of material and intellectual resources;

- formation of a simulation model of adaptive management of the MPhCo, which is the basis of the support system for management decisions;

- development of an algorithm for the practical use of the simulation model and the corresponding organizational and technical support;

- continuous public relations of the enterprise;

- improvement of information and communication support of economic entities of the pharmaceutical industry.

The listed directions of increase of adaptive management efficiency of MPhCo in practice will give pharmaceutical branch and the enterprises real opportunities of achievement a certain competitiveness level, reception of competitive advantages on indicators of the management level in modern economic conditions.

Thus, improving adaptive management in the formation of competitive advantages of the $\mathrm{MPhCo}$ requires businesses to be determined, flexible and adequate both in the formation of modern management strategies and in tactical planning and implementation of operational tasks for the current production and economic and commercial activities.

Study limitations. Missing research is possible only in a market-driven economy.

The prospect of further research should be to determine the current state and improve the quality of management decisions for the development of manufacturing pharmaceutical companies.

\section{Conclusions}

The directions of increasing the adaptive management efficiency are determined and it is concluded that the main criterion of efficiency is the quality of pharmaceutical products and the quality of management decisions in economic risks.

The study proved that these areas of improving the adaptive management effectiveness in $\mathrm{MPhCo}$, in practice provide real opportunities for the pharmaceutical industry to achieve a certain level of competitiveness as pharmaceutical manufacturers and gain competitive advantage in terms of management.

It is noted that the improvement of adaptive management in forming of competitive advantages in the MPhCo should be considered in terms of the following factors of influence: socio-economic, organizational-economic, organizational-legal, organizational-technical, organizational-technological.

\section{Conflict of interests}

The authors declare that they have no conflict of interests.

\section{Financing}

The study was performed without financial support.

\section{References}

[1] Siketina, N. H.; Bezpartochnyi, M., Britchenko, I. (Eds.) (2019). Adaptive development of competitive advantages of an industrial enterprise on the basis of analysis and ensuring the competitiveness of its products. Conceptual aspects management of competitiveness the economic entities. Vol. 2. Przeworsk: WSSG, 98-107.

[2] Farhshatova, O., Zaharov, S., Vereskun, M., Kolosok, V. (2019). Formation of Competitive Advantages of the Enterprise Based on Adaptive Management. Marketing and Management of Innovations, 1, 244-256. doi: http://doi.org/10.21272/mmi.2019.1-21

[3] Starikova, M. S., Mishin, D. A., Nikitina, E. A. (2016). Assessment of Quality of Adaptive Management of Industrial Corporation in the Competitive Environment. International Journal of Pharmacy \& Technology, 8 (4), 22473-22485.

[4] Sieckmann, F., Ngoc, H. N., Helm, R., Kohl, H. (2018). Implementation of lean production systems in small and medium-sized pharmaceutical enterprises. Procedia Manufacturing, 21, 814-821. doi: http://doi.org/10.1016/j.promfg.2018.02.188

[5] Anusha, K., Krishna, P. P., Praveen, K. V. (2014). Pharmaceutical product management. The Pharma Innovation Journal, $6(11), 112-114$.

[6] Bondarieva, I. V. (2011). Naukovo-metodychni pidkhody do adaptyvnogho upravlinnia farmacevtychnymy orghanizaciiamy. Kyiv, 23. 
[7] Pestun, I. V., Mnushko Z. M. (2008). Stan ta perspektyvy makrootochennia na diialnist farmatsevtychnykh orhanizatsii v Ukraini. Upravlinnia, ekonomika ta zabezpechennia yakosti v farmatsii, 1, 8-14.

[8] IEC 31010:2019 Risk management - Risk assessment techniques (2019). International Standard, 264.

[9] Raue, J. S., Wieland, A. (2015). The interplay of different types of governance in horizontal cooperations: A view on logistics service providers. The International Journal of Logistics Management, 26 (2), 401-423. doi: http://doi.org/10.1108/ ijlm-08-2012-0083

[10] Adobor, H. (2020). Supply chain resilience: an adaptive cycle approach. The International Journal of Logistics Management, 31 (3), 443-463. doi: http://doi.org/10.1108/ijlm-01-2020-0019

[11] Prasanth, S. P., Jagathy, R. V. P., Pramod, V. R. (2015). Total Productive Maintenance And Role Of Interpretive Structural Modeling And Structural Equation Modeling In Analyzing Barriers In Its Implementation - A Literature Review. International Journal of Scientific \& Technology Research, 4 (9), 302-315.

[12] Sundareshan, S. D. (2015). A Literature Review on Lean Implementations - A comprehensive summary. International Journal of Engineering Research and Applications, 1 (5), 73-81.

[13] Zlatko, N., Vojko, P., Marina, D. (2015). Current and future use of management tools. Ekonomika a management, 18 (1), $28-45$. doi: http://doi.org/10.15240/tul/001/2015-1-003

[14] Problems and prospects of pharmaceutical companies in Ukraine. Available at: https://pro-capital.ua/press_center/procapprog/ view/12/

[15] Sahaidak-Nikitiuk, R., Holybtsova, K., Demchenko, N., Zarichkova, M. (2020). Theoretical and applied aspects of adaptive management of manufacturing pharmaceutical enterprises of Ukraine. ScienceRise: Pharmaceutical Science, 6 (28), 68-73. doi: http://doi.org/10.15587/2519-4852.2020.222219

[16] Sahaidak-Nikitiuk, R. V., Holybtsova, K. K. (2020). Analysis of existing approaches to adaptive enterprise management. Social pharmacy: status, problems and prospects, 247-250.

[17] Bellm, D. (2015). Operational Excellence in the Pharmaceutical Industry - An Architecture for Emerging Markets. St. Gallen: The University of St. Gallen, 316.

[18] Sahaidak-Nikitiuk, R. V., Holybtsova, K. K. (2020). Research of external factors and internal situation of functioning of pharmaceutical enterprises. Theoretical and practical aspects of drug research, 225-226.

[19] Kemeni, J., Snell, J. (1972). Cybernetic Modeling: Some Applications. Moscow: Soviet Radio, 192.

[20] Farhshatova, O., Zaharov, S., Vereskun, M., Kolosok, V. (2019). Formation of Competitive Advantages of the Enterprise Based on Adaptive Management. Marketing and Management of Innovations, 1, 244-256. doi: http://doi.org/10.21272/mmi.2019.1-21

How to cite: Sahaidak-Nikitiuk, R., Holybtsova, K., Demchenko, N., Nikitiuk, V. (2021). Directions for improving adaptive management efficiency of manufacturing pharmaceutical companies. EUREKA: Health Sciences, 5, 61-68. doi: http://doi.org/10.21303/ 2504-5679.2021.002052 